\title{
ACTIVISMO, MOVIMIENTOS Y PARTICIPACIÓN SOCIAL DE LAS PERSONAS CON DIVERSIDAD FUNCIONAL DURANTE LA TRANSICIÓN A LA DEMOCRACIA
}

\section{ACTIVISM, MOVEMENTS AND SOCIAL PARTICIPATION OF PEOPLE WITH FUNCTIONAL DIVERSITY DURING THE SPANISH TRANSITION TO DEMOCRACY}

\author{
Emilia Martos Contreras \\ Universidad de Almería (España) \\ ORCID: https://orcid.org/0000-0003-1705-5721
}

Recibido el 9-9-2017 y aceptado el 18-12-2017

\begin{abstract}
Resumen: Las personas con diversidad funcional sufrieron con mayor incidencia las limitaciones y las carencias del sistema dictatorial y sus políticas sociales. Sin embargo, al igual que ocurrió en otros puntos del mundo, a mediados del siglo se fue gestando un importante cambio de consciencia y un espíritu crítico que se consolidó a la muerte de Franco. De hecho, la transición política a la democracia fue entendida como una oportunidad de cambio y un momento histórico clave para la consecución de la igualdad de derechos. Este texto, basado en una investigación mucho más amplia, analiza la participación de las personas con diversidad funcional en la construcción de la democracia. Para ello nos acercamos tanto a la participación directa en la política como, sobre todo, al activismo específico que consideramos colaboró en la evolución social de la naciente democracia. Además, sin ser el objetivo principal de esta aportación, hacemos referencias a las numerosas dificultades que afrontaban estas personas y sin las cuales no se podría entender el significado de estos movimientos sociales. Debido a la práctica ausencia de bibliografía secundaria hemos utilizado principalmente fuentes hemerográficas y orales, además de testimonios escritos rescatados de bibliografía divulgativa de la época.
\end{abstract}

Palabras clave: diversidad funcional, transición a la democracia, movimientos sociales, participación política, problemas sociales. 


\begin{abstract}
People with functional diversity suffered with greater incidence the limitations and deficiencies of the dictatorial system and its social policies. However, as in other parts of the world, in the middle of the century, a significant change of conscience took place. This critical spirit was consolidated in the death of Franco. In fact, the political transition to democracy was understood as an opportunity for change and a key historical moment for the achievement of equal rights. This text, based on a much wider research, analyzes the participation of people with functional diversity in the construction of democracy. To this end, we are approaching both direct participation in politics and the specific activism that we consider to be key to understanding the evolution of the welfare state in Spain. Moreover, without being the main objective of this contribution, we make reference to the numerous difficulties faced by these people, necessary to approach the real meaning of these social movements. Due to the absence of secondary bibliography, we have mainly used oral and hemerographic sources, in addition to written testimonies rescued from divulgation books at the time.
\end{abstract}

Keywords: Disability History, transition to democracy, social movements, political participation, social problems. 


\section{Introducción}

Salvo en muy contadas ocasiones, la discapacidad no ha sido objeto de estudio de los historiadores, ni siquiera después del creciente interés por los nuevos movimientos sociales o las investigaciones sobre minorías marginadas. De hecho, no ha sido hasta bien entrado el siglo XXI que se ha empezado a forjar una nueva rama historiográfica, conocida como Disability History Studies, y que pone el interés sobre este enorme vacío historiográfico. ${ }^{1}$ Con una fuerte influencia de los interdisciplinares Disability Studies, y ante el gran campo inexplorado, los primeros investigadores en este ámbito se han centrado especialmente en la historia reciente de sus países de origen, destacando los trabajos surgidos en Estados Unidos. ${ }^{2}$ No en vano, este país fue la cuna de uno de los movimientos sociales más originales y decisivos en la evolución de los derechos de las personas con diversidad funcional, el llamado Independent Living, encabezado por el activista Edward. V. Roberts. ${ }^{3}$ Este movimiento forjó desde mediados de los años sesenta un nuevo modelo de comprensión de la discapacidad renovado y transgresor que, en muchos aspectos, supuso la base de los principios que conforman los estudios sobre la diversidad funcional. En el caso español, las investigaciones históricas centradas en esta temática han sido hasta hace unos años inexistentes, salvo algunos trabajos de referencia surgidos de otras áreas de estudio, especialmente desde el ámbito de la educación o la medicina. ${ }^{4}$ Este es el contexto en el que se

${ }^{1}$ Se considera como texto básico, aunque no fuese la primera reflexión, el documento de Kudlick, 2003.

2 Una de las obras referentes es sin duda la de Doris y Frieda Zames, en la que, a través de más de 100 entrevistas, completadas con fuentes secundarias, repasaron el surgimiento y desarrollo hasta el cambio de siglo, de estos movimientos sociales en Estados Unidos. Zames y Zames, 2001.

${ }^{3}$ Véase sobre este activista la entrevista realizada dentro del programa de Historia Oral del Estado de California. O'Hara, 1994.

${ }^{4}$ En el año 2005 arrancó un proyecto de investigación coordinadora, proveniente del campo de la medicina y centrado en la historia de la poliomielitis en España. Dirigidos por los catedráticos José Antonio Rodríguez Sánchez y Rosa Ballester Añón, fue quizás la primera línea de investigación que trató algún aspecto de discapacidad desde el punto de vista histórico, sobre todo la obra Porras et.al. 2013. Aunque anteriormente se había creado, también desde la historia de la medicina, la llamada Historia de las Deficiencias, Aguado, 1995. Véase también «Dossiere: Políticas, respuestas sociales y movimientos asociativos frente a la poliomielitis: experiencia europea», Dynamis, vol. 32, n. ${ }^{\circ}$ 2, 2012, «Dossier: La poliomielitis y sus contextos: experiencias colectivas e individuales ante la enfermedad en el siglo XX», Asclepio, vol. 61, n. 2 (2012). 
elaboró la investigación doctoral que sustenta esta aportación. ${ }^{5}$ Debido a la casi absoluta ausencia de fuentes historiográficas previas, el trabajo se centró específicamente en la recopilación de fuentes bibliográficas primarias y material archivístico de todo tipo, incluido fuentes hemerográficas y orales. ${ }^{6}$ La aportación que aquí proponemos es una maduración y síntesis de una parte de ese trabajo, acotado a los años de transición política a la democracia. Somos conscientes que la novedad de la temática implica la necesidad de una profusa aclaración de conceptos y afirmaciones, no obstante, las obvias limitaciones de espacio nos han llevado a preponderar la línea argumentativa, así como dejar para un trabajo posterior, el análisis comparativo con otros movimientos sociales de la época. ${ }^{7}$

\section{La participación de las personas con diversidad funcional en la construcción democrática}

Las primeras interpretaciones historiográficas de la transición situaron a las élites políticas en el centro del proceso, lo que dejaba a la sociedad en un segundo plano casi residual. ${ }^{8}$ Sin embargo, desde el cambio de siglo parece haber un creciente consenso, al menos entre historiadores, a la hora de resaltar la importancia de los movimientos sociales. En estas interpretaciones se ha repetido constantemente el concepto de la presión «desde abajo», lo que incluye tanto la movilización social como la electo-

5 Martos, 2014.

6 A parte de los diferentes trabajos que ha ido publicando la misma autora de este artículo, en los últimos años han aparecido también otros trabajos relacionados con la temática, destacando especialmente los de los investigadores Brégain, Cura y Mártínez. Véase, por ejemplo: Bregain, 2014; Cura, 2016, Martínez y Cura, 2017 y el especial: «Exploring human diversity: a dossier devoted to disability history», Asclepio, n. ${ }^{\circ} 68$ (2), 2016.

${ }^{7}$ En cuanto a la decisión de usar el término «diversidad funcional», frente al de «persona con discapacidad» nos basamos en una reflexión teórica previa que por cuestiones de espacio no podemos desarrollar. En todo caso, no renegamos del uso de la palabra «discapacidad», que no obstante restringimos para referirnos a los aspectos médicos. Sin embargo, cuando hablamos del heterogéneo colectivo de personas que aquí nos ocupa, consideramos mucho más acertado el calificativo que señala la «diversidad de las funciones», que fue, al fin y al cabo, lo que les llevó a ser considerados diferentes a lo largo de la historia. Véase sobre este término Romañach y Lobato, 2005.

${ }^{8}$ En esta línea fue el primer trabajo histórico sobre la transición de Tusell,1991. Sin embargo, el mismo autor fue evolucionando y consolidando la incorporación de los actores colectivos. 
ral, como medios que marcaron el camino del proceso de transición..$^{9} \mathrm{Al}$ origen de estos planteamientos estuvieron las investigaciones centradas en los movimientos obreros, y que actualmente ya suponen una bibliografía clásica e imprescindible para la comprensión de este periodo de investigación. ${ }^{10}$ Sin embargo, una vez reconocida la influencia social sobre el proceso democrático, se había abierto el camino para plantear la importancia de otros colectivos. En esta siguiente ola se pueden encuadrar las investigaciones sobre la participación femenina y también de organizaciones como las asociaciones de vecinos. Estos estudios pronto descubrieron otras vías participativas y de protesta, que se alejan de las tradicionales estrategias obreras, y que por tanto estaban abriendo un nuevo campo de interpretación. ${ }^{11}$

A la hora de estudiar la participación de las personas con diversidad funcional en la democracia, tenemos que tener en cuenta todas estas experiencias historiográficas, pero también estar abiertos a nuevos enfoques y estrategias. Una de las principales dificultades a la hora de afrontar esta empresa es el reducir a este heterogéneo grupo de personas a un «colectivo», cuando son obvias las profundas diferencias y necesidad de sus integrantes. Aun así, y tras haber investigado el periodo que nos ocupa, sí creemos que existe una serie de coincidencias, especialmente en las necesidades y reivindicaciones, que nos permite acotarlos a un colectivo, al menos en esta aproximación general a la temática. Entre esas coincidencias se encuentra la alarmante e indiscutible marginalidad de todas aquellas personas que la sociedad de la época etiquetaba como «minusválido» o «subnormales». Aunque en teoría el primer término hacía referencia a discapacidad física y el segundo a intelectual, en la práctica se confundían, mezclaban e intercambiaban incluso con las discapacidades sensoriales. No en vano, desde pequeños todos los afectados sufrían las mismas limitaciones a la hora de recibir la atención sanitaria específica o incluso, la atención educativa básica. Mientras que el alumnado en sillas de ruedas quedaba fuera del colegio porque no podía subir las escaleras, el que mostraba diferencias en el proceso de aprendizaje era apartado o, en el mejor de los casos, desplazado a un colegio de «Educación Especial». Así es como la mayoría de los afectados abandonaban su formación añadiendo

\footnotetext{
${ }^{9}$ Esa idea ya fue planteada en Maravall, 1982.

10 Véase por ejemplo Adell, 1989; Soto, 1993; Ruiz, 1993; Marín, 1997 y Soto y Aroca, 2012.

11 Véase Ortiz, 2008 y Quirosa, 2011.
} 
dificultad a la verdadera batalla del colectivo, que era la de encontrar trabajo. Una excepción particular fueron las oportunidades ofrecidas por la ONCE que, a pesar de sus destacables limitaciones, tanto en la oferta educativa como la profesional, supuso un avance con respecto al panorama desolador al que se enfrentaban los demás colectivos. Por otra parte, las mujeres tuvieron que lidiar con una doble discriminación que, no solo las encerraba indefinidamente en el ámbito doméstico, sino que además les negaba, por sus particularidades, el acceso al único camino de prosperidad que estaba socialmente permitido: el matrimonio y la procreación. Aunque esta descripción somera puede parecer una generalización excesiva, podemos afirmar con rotundidad que esa realidad excluyente y marginadora fue un hecho que, además, a pesar de algunas características diferenciadoras, fue homóloga a todas las personas que en aquella época eran etiquetadas como «inválidas». ${ }^{12}$ No obstante, esta marginalidad, no nos debe llevar a la errónea interpretación de unos personajes pasivos y autocomplacientes con la realidad. De hecho, esta interpretación no sería más que una continuación del proceso de marginación y de comprensión de la diversidad funcional como un hecho «discapacitador» tanto para ocupar un puesto social como para reivindicarlo. Muy al contrario, la propia constancia de quejas sobre la situación de las personas con diversidad funcional nos muestra la existencia de un espíritu crítico e inconformista. Ya desde el inicio del franquismo tenemos señales de los intentos asociativos, y los pocos testimonios archivísticos o hemerográficos no hacen justicia de esta actividad, aunque en su mayoría fuese frustrada y no diese resultados concretos hasta años después. En todo caso, nuestra intención no es sobredimensionar una realidad histórica generalizando sobre este heterogéneo colectivo al insistir en las actitudes reivindicativas más llamativas del periodo. No obstante, y ese si es el objetivo de esta aportación, queremos llamar la atención sobre ejemplos de movilización y participación ciudadana, que rompen con las ideas de pasividad preconcebida y que además nos permiten visibilizar una realidad que no ha sido tomada en consideración por la historiografía. El estudio de las actitudes combativas de las personas con diversidad funcional son un máximo ejemplo de cómo en el seno de la sociedad civil española se creaban dinámicas regenerado-

12 A estas conclusiones ha contribuido el análisis de más de una decena de cabeceras de prensa general, así como revistas específicas como Minusval y Voces. También han influido de manera decisiva los testimonios de la época, mucho de ellos recogidos en bibliografía primaria, además de las entrevistas realizadas a personas implicadas. 
ras y de cambio, y cómo la presión de los implicados moduló la evolución del proceso de transición a la democracia. Como veremos, entre los diferentes partidos políticos la situación de las personas con diversidad funcional no tenía ninguna presencia y, aun así, en el año 1981 se aprobó la Ley de Integración del Minusválido (Lismi). La norma se aprobó tarde, y con importantes deficiencias, pero esto, de nuevo, no dejó de ser más que otra señal del enorme trabajo que supuso poner la temática sobre la mesa, y convertirla en interés nacional.

\section{Acción política desde los partidos y los puestos de poder}

Se puede afirmar con rotundidad que durante todo el periodo que nos ocupa, las personas con diversidad funcional no llegaron a ocupar prácticamente ningún puesto político de dirección o representación en ninguno de sus estratos, ni siquiera en las bases. Los pocos casos extraordinarios, que citaremos posteriormente, son tan solo la excepción que confirman la regla: la marginación social de estas personas. En realidad, esta ausencia en los puestos de poder de los recientes partidos era tan solo un reflejo de su papel en la sociedad. Como norma en ningún puesto de mando, dirección o representación podíamos encontrar personas con diversidad funcional. Lejos había quedado el corto periodo de posguerra en el que los heridos, los del bando ganador se entiende, habían ocupado un espacio público de cierta relevancia, no solo por los puestos de trabajo que les reservó el franquismo, sino también por el lugar social que les designó como héroes y mártires en vida. ${ }^{13}$ La realidad es que en los años setenta las personas con diversidad funcional apenas tenían opciones para encontrar trabajo, mucho menos para situarse en puestos de mando. Como dijimos, había alguna excepción en el caso de las personas con discapacidad visual, aunque siempre en relación con la Organización Nacional de Ciegos (ONCE) a la que pertenecían. Este organismo que se había planteado antes de la guerra civil, se terminó consolidando como una realidad en los primeros momentos de la contienda, en el bando nacional. Aun a pesar de su adaptación al régimen dictatorial, mantuvo con cierto rigor el intento de la autogestión, lo que permitió que personas con discapacidad visual llegasen a puestos de dirección de la organización, así como a otros

\footnotetext{
13 Martos, 2016-b.
} 
puestos educativos y profesionales de sus centros. ${ }^{14}$ Sin embargo, fuera de esos escasos «espacios protegidos», la realidad para los afectados era un camino plagado de barreras, tanto arquitectónicas, como sociales y culturales. Un ejemplo muy simbólico, y además en estrecha relación con el aspecto que nos ocupa, lo representaron las barreras arquitectónicas que protagonizaron los comicios de los años de transición. A las dificultades ordinarias para entrar en los colegios electorales, se unieron las limitaciones de espacio y la forma de las cabinas de votaciones, y que fueron denunciadas tanto en la revista Minusval, como en el diario Ya: «¿de qué forma van a poder elegir la papeleta las personas minusválidas que, por usar sillas de ruedas, no puedan entrar en esas cabinas? ¿Cómo se les va a garantizar el secreto del voto si tienen que pedir a cualquiera la papeleta? Esto es una incógnita que precisa solución con el tiempo necesario». ${ }^{15}$

Pero como hemos dicho, a pesar de todas estas limitaciones, hubo algunas excepciones extraordinarias. El caso más conocido fue el del vasco Miguel Pereyra Etchevarría. El joven profesor había estudiado la carrera de filosofía, y estaba terminando la de Teología, cuando debido a un accidente de coche quedó tetrapléjico. Su familia tenía una estrecha relación con el bando franquista, lo que según la memoria del activista contribuyó a que hubiese tenido una infancia relativamente feliz y tranquila. Desde pronto desarrolló un creciente interés por las cuestiones sociales, que en un principio le llevó a decantarse por incorporarse a la Orden de los Jesuitas. Sin embargo, conforme avanzó sus estudios fue aumentando su espíritu crítico: «Estudiar Filosofía desmontó mi contexto del catolicismo. Esos tres años me abrieron los ojos a la realidad y descubrí la injusticia social» ${ }^{16}$. Su creciente inconformismo empezó a hacerse patente en la asignatura que impartía «Formación del Espíritu Nacional»: «El colegio recibió algunas quejas por mis explicaciones, que consideraban fuera de lugar. Era la doctrina social de la iglesia. Empecé a ser molesto y, sin realizar los tres años que correspondían, el provincial me destinó para hacer Teología en Irlanda». ${ }^{17}$

Cuando poco después sufrió el accidente, Miguel Pereyra estuvo decidido a continuar con su vida. Gracias al apoyo de sus compañeros, y a

14 Sobre la historia de la ONCE véase especialmente la pionera obra de Montoro, 1991 y las vivencias del primer presidente de la misma Javier Gutiérrez de Tovar y Beruete, en Gutiérrez, 1988.

${ }^{15}$ Ya, 12.5.1977 y Minusval, n. . 19, junio de 1977.

16 Ledesma, 2012, p. 15.

17 Ibidem, p. 16. 
pesar del año que estuvo internado en un hospital, prosiguió con sus estudios. Continuó con su espíritu crítico, y a partir de entonces empezó a colaborar con una de las pocas organizaciones específicas relacionadas con la discapacidad, la Fraternidad Cristiana (Frater). ${ }^{18}$ En el año 1968 fue ordenado sacerdote, lo que en sí supuso un importante reto. Sin embargo, Miguel Pereyra pronto decidió desarrollarse profesionalmente fuera de la Iglesia, y así fue como empezó su carrera profesional al frente de instituciones educativas específicas. Dentro de su carrera profesional destaca la subdirección del Centro Nacional de Parapléjicos en Toledo, donde jugó un papel importante en la modernización del centro. ${ }^{19}$ Como activista escribió un manifiesto de diez puntos que llegó a presentar a varios ministros de Franco. Posteriormente, ya en los años de la transición, estuvo en la base de la creación de la Coordinadora Estatal de Minusválidos Físicos de España y, de hecho, fue su secretario general. Para esa misma época Miguel Pereyra ya se había afiliado al Partido Socialista. A través de este partido decidió presentarse a las primeras elecciones democráticas de $\mathrm{Ar}$ gés (Toledo), resultando elegido como concejal. Posteriormente, cuando en 1983 ganó en el municipio el partido socialista, Miguel Pereyra era el cabeza de lista, convirtiéndose en el primer alcalde con tetraplejia de la historia de España. En realidad, en ese mismo año y ya fuera de lo que consideramos periodo de la transición, no fue la única persona con diversidad funcional que consiguió un puesto en un consistorio. Así, el jovencísimo Antoni Millán Moya, ocupó la concejalía municipal de Granada, también en esta ocasión dentro de las listas del PSOE. Según lo describe Ledesma Heras:

A pesar de ir sentado a todas partes, Millán era un «culo inquieto», tanto que sus andanzas llegaron pronto a oídos del entonces alcalde de Granada, Antoni Jara, quien le propuso ir de candidato a concejal en las listas del PSOE. Aunque era virgen en las lides de la política, aceptó el reto y resultó elegido concejal en las elecciones municipales de $1983 .{ }^{20}$

Antoni Millán había quedado parapléjico en su adolescencia, debido a una enfermedad. Sin embargo, gracias al apoyo de los compañeros, consiguió retomar sus estudios, terminar la secundaria y realizar la carrera de

\footnotetext{
18 Pereyra, 2012.

19 Pérez, 1999, p. 62.

${ }^{20}$ Ledesma, 2012, p. 180.
} 
Graduado Social en la Universidad de Granada. Otra activista que participó en una lista electoral de estos primeros años democráticos fue la joven Pilar Ramiro Collar. A contracorriente de todas las normas socialmente aceptadas se presentó en el año 1979 a candidata al consistorio de Madrid dentro de las listas de Organización Revolucionaria de Trabajadores. ${ }^{21}$ Aunque a los 8 años la polio le obligó a empezar a desplazarse con una silla de ruedas, y tuvo que dejar el colegio, la joven se negó a quedarse en casa. De hecho, con la ayuda de sus hermanos, consiguió llegar a la universidad. Aquí fue donde entró en contacto con los movimientos de izquierdas y la organización Minusválidos Unidos, de la que fue secretaria. Revolucionaria en muchos aspectos, con 24 años se fue de casa para vivir en un piso compartido, donde «repartíamos todas las tareas domésticas de igual a igual hombres y mujeres.» ${ }^{22}$ No obstante, a pesar de la incursión de Pilar Ramírez en la política, hay que señalar que en los años que nos ocupan se centró específicamente en el activismo en torno a la diversidad funcional, convirtiéndose en un verdadero referente y una pieza clave para entender el desarrollo y aprobación de la Ley de Integración social del Minusválido.

Aunque como hemos remarcado la presencia de las personas con diversidad funcional en puestos políticos fue prácticamente inexistente, sí hay que decir que hubo una clara implicación de este heterogéneo colectivo con los partidos políticos del periodo. En muchos casos hubo una militancia activa, y así nos lo dejan entrever las imágenes de manifestaciones específicas de la época. También hemos encontrado algún ejemplo, como el de la asociación Minusválidos Unidos descrita por Wilhelmi Casanova, donde se indica que la organización nació como consecuencia de la militancia en diversos partidos políticos. Sin embargo, y como también apoya el mismo autor, en muchas ocasiones se dio una doble militancia que no siempre fue fácil y a menudo creó conflictos de intereses y tensiones internas. ${ }^{23}$ Como ocurrió con otras demandas sociales durante los años de la transición política hubo enfrentamientos entre los que eran partidarios de priorizar el cambio político frente a los que propugnaban la urgencia de cambios prácticos inmediatos. Esta realidad seguramente colaboró

${ }^{21}$ El País, 29.3.1979, El País, 23.01.1979 y «Listas completas de candidatos a las elecciones generales», ABC, 10.3.1979, p. 25.

22 Entrevista a Pilar Ramiro Collar por Wilhelmi Casanova citada en Wilhelmi, 2011, p. 300 .

23 Ibidem, p. 287. 
a que muchos activistas se decantaran por la lucha específica, como ya vimos en el caso de Pilar Ramiro. El almeriense José Gómez Amate, posterior presidente de la asociación provincial Verdiblanca, recordó las dificultades para integrarse en las bases de los partidos políticos de la época y justificó así su decisión de optar por el asociacionismo religioso de la Fraternidad Cristiana:

una persona con discapacidad en un partido político era un persona pues que estaba allí sentado pero más bien ignorado, entre otras cosas porque en aquellos tiempos había que correr, porque si no corrías te cogían... y bueno pues pusimos en marcha lo que es un movimiento asociativo que lo que pretendía era unir, aunar el esfuerzo y algún tipo de representatividad (...) para nosotros era una forma de participar entre comillas en política porque teníamos una organización que era religiosa pero no era confesional y al no ser confesional (...) teníamos capacidad para decir cosas y manifestarnos. ${ }^{24}$

A pesar de las simpatías y las sinergias puntuales, la tendencia fue hacía un asociacionismo específico, y relativamente desligado de los partidos. Así, por ejemplo, según el recuerdo del activista Eugeni Pérez:

En general, se trataba de movilizaciones autónomas, donde las posiciones políticas eran individuales y los partidos no estaban mezclados como grupos de presión. La unidad no se cuestionaba; lo que importaba en esos momentos era la lucha concreta, y los pasos que se estaban dando dejaban en segundo término las polémicas políticas. ${ }^{25}$

Una de las razones que seguramente influyó en esta preferencia por el asociacionismo específico fue la constatada falta de interés por parte de los partidos políticos. Aunque se crearon acuerdos y firmaron algunos compromisos, la tendencia general fue al absoluto olvido, más allá de las escuetas frases en los libros electores que prometían «especial atención a los problemas de los minusválidos y subnormales», surgidas de partidos tan dispares como Alianza Popular o el Partido Socialista. ${ }^{26}$ Esto no significa que no hubiese actuaciones conjuntas, especialmente en las bases. Sobre todo, cuando las asociaciones específicas ya estaban creadas y em-

\footnotetext{
24 Entrevista a José Gómez Amate, Almería, 25.4.2011.

25 Pérez, 1994, p. 58.

26 Martos, 2011.
} 
pezaban a tener una cierta fuerza, encontramos apoyos por parte de ciertos partidos. Así, por ejemplo, en el caso de la provincia de Almería, el PSOE cedió temporalmente un espacio para que la Asociación de Sordos de Almería pudiese desarrollar un centro ocupacional. ${ }^{27}$ También el presidente de Verdiblanca, la asociación de personas con diversidad funcional física de Almería, recuerda haber tenido contacto con ciertos políticos, de diversos partidos de izquierdas, con la intención de conseguir apoyos para mejoras estructurales en el centro de la ciudad. ${ }^{28}$ Además, hubo ocasiones en los que la sensibilidad de políticos determinados, que podríamos considerar independientemente de su partido y más asociada a cuestiones personales, llevó al apoyo de la causa. El caso más significativo fue, sin duda, el de Ramón Trías Fargas, diputado de EDC y CIU, reconocido como impulsor político de la Ley de Integración del Minusválido. ${ }^{29}$ Por otra parte, las pocas intervenciones al Senado que se hicieron para reclamar alguna temática relacionada con la diversidad funcional, vinieron precisamente de la mano del senador por Almería Juan de Dios Heredia. ${ }^{30}$ Sin embargo, no cesamos en insistir que, a la hora de la verdad, otros asuntos ocupaban la agenda política con mayor premura, y las demandas de las personas con diversidad funcional quedaron continuamente en el último plano. Como otros activistas de la época, el presidente de Asociación de Sordos de Almería, Gregorio Vílchez Rueda recuerdaba: «Los políticos prometen mucho pero no hacen tanto... no dieron mucha ayuda». ${ }^{31}$

\section{Construcción social a través del asociacionismo específico}

Fuera de los partidos políticos, la transición a la democracia y su efervescente actividad social ofreció un creciente número de posibilidades para la participación. Uno de estos pilares socializadores básicos

${ }^{27}$ Carta del secretario general, Jesús Fernández Capel, Almería, 13.11.1980, Archivo de Asoal. La prensa se hizo eco de esta oferta en La Voz de Almería, 18.11.1980, p. 12 e IDEAL, 28.11.1980, p. 12 .

${ }^{28}$ José Gómez Amate, presidente de Verdiblanca, recuerda: «El partido Andalucista tenía varios tíos muy buenos, pero también el Partido Comunista y el PSOE». Entrevista a José Gómez Amate, Almería, 25.4.2011.

29 De hecho, en el 30 aniversario de la ley el congreso de los diputados rindió homenaje al antiguo diputado, por considerarlo el «impulsor de la ley». El Mundo, 29.5.2012.

30 Martos, 2016, pp. 215-227.

31 Entrevista a Gregorio Vílchez Rueda, Almería, 25.6.2011. 
y determinantes en el proceso fueron los sindicatos. Sin embargo, en el caso que nos ocupa, el acceso a los mismos fue muy restringido. La activista Carme Serasol recuerda que en 1977 se dirigió «a varios sindicatos con los problemas de los minusválidos, pero en ninguno nos hicieron caso». Sólo encontró apoyo en SOC, donde «Xavier Casassas me ofreció la posibilidad de estar en el Comité Ejecutivo como representante y portavoz de los minusválidos». ${ }^{32}$ Esta dificultad de incorporación en los sindicatos se debió principalmente a la escasa relación de las personas con diversidad funcional con el empleo, de forma que la misma marginación laboral les dificultó la integración en los principales organismos de presión en esa temática. Con la creación en los años setenta de las Comisiones de Pensionistas y Jubilados se abrió la vía de participación a un pequeño sector de los afectados, los llamados «pensionistas». Se trataba, por norma general, de hombres cuya vida laboral se había visto truncada por algún accidente o enfermedad y que, en gran parte, contaban con algún tipo de prestación económica, aunque esta solía ser ínfima. ${ }^{33}$ No obstante, el perfil y los objetivos específicos de estas comisiones, principalmente centradas en el tema de la jubilación, no encajaban con las necesidades de las personas con diversidad funcional, ya que una de sus principales demandas era el empleo y no las contribuciones públicas. No fue hasta varios años después, ya en los años ochenta, cuando los sindicatos mayoritarios empezaron a contemplar a las personas con diversidad funcional como un colectivo con necesidades a atender, lo que coincidió, y no por casualidad, con la incorporación de los sindicatos en los órganos de gestión del Inserso. ${ }^{34}$ En 1982, CCOO creó la Comisión Sindical de Minusválidos, justificando en la editorial de su boletín algo que la misma CCOO había tardado varios años en reconocer, y que aún sería tarea pendiente de otros sindicatos:

A mucha gente, incluidos disminuidos físicos, puede parecerle algo extraño la creación de esta Comisión (...) la sociedad capitalista, causante en parte de esta elevada tasa de minusválidos, por la deficiente estructura sanitaria, rechaza la integración de este amplio colectivo, al que considera incapaz de participar en el proceso productivo, lo margina, y establece una serie de canales (legislación, instituciones, etc.) «protec-

\footnotetext{
32 Serasols, 1994, pp. 161-162.

33 Martos, 2014.

34 Martos, 2017.
} 
tores» para lavarse la conciencia y tener los menos problemas posibles (...) Uno de los derechos universales, recogidos en nuestro texto constitucional, es el derecho al trabajo. (...) Es preciso además luchar por conquistarlo (...) pensamos que los trabajadores minusválidos, forman parte plenamente de la clase obrera y deben participar en sus organizaciones y sus luchas como cualquier otro de sus miembros. ${ }^{35}$

Por todo lo expuesto, se entiende que la principal colaboración de las personas con diversidad funcional en la construcción democrática se dio fuera de los partidos políticos o de los sindicatos. De hecho, como vimos en el testimonio de Gómez Amate, algunos eran conscientes que su participación era una forma de hacer política. Y así fue, ya fuese a través de las movilizaciones más mediáticas, como a través de la ingente labor realizada en torno a la Ley de Integración Social del Minusválido. Lo cierto es que sería imposible entender el cambio social y político en torno a la discapacidad, sin tener en cuenta el papel protagonista desempeñado por los implicados y la presión ejercida por los mismos. Por otra parte, no podríamos explicar la construcción de una sociedad democrática, sin la evolución de sus conceptos de igualdad e inclusión social. Aunque esta evolución a la que hacemos referencia, germinó durante el franquismo y se debe entender obligatoriamente dentro de un marco internacional, es indiscutible que el ambiente de cambio y las nuevas libertades políticas dieron un impulso determinante a las movilizaciones de las personas con diversidad funcional. Aunque no contamos con datos estadísticos específicos, y los archivos hemerográficos de la época solo recogieron las acciones más significativas, tenemos evidencias de que las movilizaciones fueron recurrentes. Así, por ejemplo, contamos con documentos fotográficos, como las del Archivo del Partido del Trabajo de España y de la Joven Guardia Roja de España, en las que vemos diversas instantáneas, con una afluencia variable pero importante. Otro vestigio significativo es la experiencia de los activistas, ya sea recogida en la actualidad o al calor de los hechos, en alguno de los medios divulgativos del momento. Así, por ejemplo, según la memoria del activista Antonio Guillén: «Estas movilizaciones tuvieron un nivel de participación muy elevado de personas con disminución y en varias ocasiones se lograron concentraciones de centenares de personas, lo que constituía una movilización de este colectivo

${ }^{35}$ Minusválidos. CCOO. Boletín informativo, n. ${ }^{\circ}$ 1, junio 1982. 
sin precedentes en el conjunto del Estado español y de los restantes países europeos». ${ }^{36}$

Una de las primeras acciones de protesta que trascendió a los medios, en 1976, fue el encierro de un grupo de personas con diversidad funcional física en la parroquia de Jesús Obrero, en el barrio de San Blas, en Madrid. Los encerrados pertenecían a la Comisión de Trabajadores Minusválidos en paro de Málaga, a la Comisión para la Integración Social del Minusválido de Andalucía y Minusválidos Unidos de Madrid, y su objetivo era llamar la atención sobre su situación socio-laboral, protestando contra la ineficacia por incumplimiento de las reservas de empleo aprobadas por el franquismo. ${ }^{37} \mathrm{El}$ encierro, que duró varios días, recibió el apoyo de la organización Auxilia y atrajo la atención de trabajadores de varias empresas, asociaciones de vecinos y la Junta Sindical de Actores. ${ }^{38}$ También ese mismo año, tenemos registros de encierros en La Coruña y empezaron las movilizaciones en Barcelona. Uno de sus protagonistas, Eugeni Pérez, localiza ahí un punto álgido de lo que llamó la «rebelión de los cojos» ${ }^{39} \mathrm{y}$ recuerda en la obra colectiva Crónica de una lucha por la igualdad, que en junio de 1976 tuvo lugar

una gran manifestación en la Plaza Sant Jaume: los manifestantes interrumpieron el tráfico en la calle Ferrán y en las Ramblas, donde centenares de personas se fueron agregando a la manifestación que los alentaban coreando con ellos los eslóganes que se gritaban: «iQueremos trabajo, transportes adaptados, calles y edificios accesibles, integración escolar! Gobierno, con quince mil pesetas, ¿qué podemos hacer?». ${ }^{40}$

Durante todo el periodo estas acciones, aun pareciendo puntuales y desconectadas continuaron al mismo ritmo que las movilizaciones sociales generales, coincidiendo con los periodos de máximo activismo. Así, por ejemplo, los puntos álgidos de movilizaciones fueron en primer lugar

36 Guillén, 1994, p. 65.

37 También la creación de un seguro de desempleo indefinido igual al salario mínimo interprofesional, independiente de si el beneficiario hubiera trabajado antes o no, así como la creación de talleres protegidos con una junta de Gobierno elegida por los trabajadores. El País, 1.10.1976.

38 El País, 3.10.1976.

39 Esta denominación ha sido reutilizada en algunas obras como por ejemplo Planella, 2012 y Planella y Pié, 2012.

40 Pérez, 1994, p. 65. 
tras las elecciones de 1976, en las que las personas con diversidad funcional habían sido completamente ignoradas y, sobre todo, después de los Pactos de la Moncloa y el descontentó que generaron en el sector. Un gran número de partidos políticos habían mostrado un compromiso pionero con la causa firmando el llamado documento «Subnormales, minusválidos y enfermos psíquicos. Documento para una alterativa democrática», el 15 de julio de $1977 .{ }^{41}$ El texto contemplaba una serie de puntos que suponían un compromiso y hoja de ruta para la actuación en el ámbito de la diversidad funcional. Sin embargo, cuando llegó la primera prueba de fuego, que fueron los Pactos de la Moncloa, casi todas las medidas quedaron en el tintero. Ni se mantuvo el compromiso presupuestario, ni se incluyó ninguna citación específica a las llamadas «medidas urgentes y realizables a plazo inmediato». FEAPS, la Federación Española de Asociaciones Prosubnormales, publicó en su órgano de expresión Voces: «en los Pactos de la Moncloa, todos se olvidan, una vez más, de los subnormales: en el pacto económico hay un compromiso de crear nuevas plazas de EGB (cubiertas ya en un $90 \%$ ) y ni se menciona la educación especial (con un escaso $25 \%$ de cobertura)». ${ }^{42}$

Esto justifica que las movilizaciones y protestas se retomasen con fuerza. Según recuerda el anteriormente citado activista Eugeni Pérez:

En ningún momento dejaron los grupos de base de manifestarse en la calle. En sus reivindicaciones, actuaron con contundencia a todos los niveles, subiendo en silla de ruedas a los autobuses y bajando al metro en un intento de mentalizar a los ciudadanos, y provocando, en éstos, reacciones contrarias, tanto en pro como en contra. (...) En aquellos días de plena euforia, apareció en la cabecera de un periódico local un

${ }^{41}$ El texto fue firmado por veinticuatro partidos políticos, cinco organizaciones sindicales, cuatro organizaciones de movimientos ciudadanos y otros diez grupos asociativos. Los partidos políticos que lo apoyaron fueron: Unión de Centro Democrático (Partido Popular, Partido Demócrata Popular, Federación Partidos Demócratas y Liberales, Partido Demócrata Cristiano, Partidos Social Demócrata, Federación social Demócrata, Partido Social Demócrata Independiente, Partido Social Liberal Andaluz, Partido Gallego Independiente, Partido Social Liberal Andaluz, Unión Demócrata Murciana, Unión Canaria, Acción Regional Extremeña), Equipo Demócrata Cristiano del Estado Español (Federación Demócrata Cristiana, Partido Nacional Vasco, Partido Popular Galego, Unión Democrática Catalana, Unión Democrática País Valenciano), Partido Comunista de España y Federación de Partidos Socialistas, Candidatura de Unidad Popular, Partido Carlista, Organización Revolucionaria de Trabajadores y Movimiento Comunista.

42 Ferrer, 2003, p. 17. 
artículo con el siguiente título: «iEl grito del minusválido!» Nunca se pudo decir mayor verdad. Este grito encendió la mecha, cual reguero de pólvora, como un revulsivo liberador en la piel de toro. Madrid, La Coruña, Andalucía, Valencia, Zaragoza... se sumaron a la moda. ${ }^{43}$

En el seno de la ONCE, donde se produjo una transición institucional, ideológica y política paralela a la estatal, se sucedieron múltiples movilizaciones y actitudes de protesta. Desde décadas anteriores en los centros educativos de la organización había empezado a forjarse un creciente movimiento estudiantil, muy crítico con el sistema político y sus rasgos que impregnaban a la ONCE. Muchos de estos estudiantes terminaron de desarrollar su conciencia ideológica en la universidad, donde participaron activamente en los movimientos estudiantiles. Mientras tanto, en el ámbito laboral, concentrada casi exclusivamente en la llamada venta del cupón, se multiplicaron las actividades de protesta, donde se exigía mejoras laborales para un sector que había perdido con la crisis su poder adquisitivo. En el caso particular de la ONCE, estas movilizaciones se canalizaron a través de los sindicatos que se crearon dentro de la organización, y que además fueron la génesis de los partidos políticos que protagonizaron la transición dentro del organismo. ${ }^{44}$

En octubre 1977, en Madrid, una decena de personas con diversidad funcional física acamparon en la Puerta del Sol en apoyo a un joven que realizaba desde hacía una semana una huelga de hambre «en pro de la inserción social de los minusválidos». ${ }^{45}$ Tras ser desalojados por la policía, una quincena de personas, la mayoría componentes de la Asamblea Permanente de Minusválidos en Lucha en Madrid, protagonizaron un encierro en la Parroquia de la Virgen del Mar, en Barrio de San Blas de Madrid. Desde aquí lanzaron una serie de reivindicaciones, entre las que destacó la «inclusión de todos los minusválidos en la Seguridad Social y puestos de trabajo o, en su defecto, la percepción del seguro del paro igual al Sueldo Mínimo Interprofesional». Además, iniciaron una campaña de recogida de firmas que, en apenas una semana, y según la prensa, superó las 8.000..$^{46}$ A finales de noviembre, coincidiendo con el fin de la Semana de Mentalización sobre la problemática del minusválido, se celebró una

\footnotetext{
43 Pérez, 1994, p. 58.

${ }_{44}$ Más sobre el movimiento sindical dentro de la ONCE en Puente, 2009.

$45 \mathrm{Ya}, 11.10 .1977$.

46 El País, 22.10.1977.
} 
manifestación por las calles de Madrid, que según El País, reunió a varias miles de personas ${ }^{47}$ Unas semanas después, unas diez personas, de nuevo definidas como «minusválidos», se encadenaron con pancartas y carteles en la Puerta del Sol de Madrid, reivindicando su derecho al trabajo y a la Seguridad Social. Tras varias horas de protesta fueron detenidos e ingresados en la Dirección General de Seguridad. Según la redacción paternalista de la prensa fue detenido «incluso uno de ellos que iba en sillas de ruedas». ${ }^{48}$

Poco después, la acción reivindicativa se reprodujo en Barcelona, donde se dio la principal acción social de este tipo. El encierro, que duró unos dos meses, arrancó con alrededor de 50 personas, aunque trascurrido un tiempo consiguió agrupar a unas 100 y creó, además, un clima general de apoyo. En el recuerdo de Eugeni Pérez:

el día 4 de noviembre de 1977, tomaron por asalto los locales del Serem en la calle Grassot como un baluarte de presión al Gobierno central. Durante los primeros días del encierro, decidieron en una asamblea llevar a cabo unas acciones muy puntuales para llamar la atención de los ciudadanos, como fueron encadenamientos en las Ramblas, la interrupción de una función en el Gran Teatro del Liceu lanzando octavillas al público...Esta noche fue de antología: los «grises» actuaron sin miramientos, repartiendo «leña» con alegría. Metieron a los activistas en las cochineras y los llevaron a comisaría. Fueron recibidos con efusivos aplausos y comprensión por parte de personas detenidas, entre las que se encontraban prostitutas y travestidos, colectivos socialmente discriminados, pero que luchan en profundidad por el problema y se suman a nuestras reivindicaciones con afecto. ${ }^{49}$

La principal reivindicación del encierro era la petición de que se reuniera la Comisión Interministerial sobre las Personas con Disminución, un organismo que se había creado en el año 1974 tras la celebración del Simposio público internacional Minusval-74, y que sin embargo no había registrado ninguna actividad palpable. Los manifestantes solicitaban que en dicha reunión se tomaran las medidas pertinentes para conseguir, entre otros objetivos, la creación de puestos de trabajo. También

\footnotetext{
${ }^{47}$ El País, 30.11.1977.

48 El País, 2.12.1977. Más sobre los estereotipos y las contradicciones del discurso periodístico de la época en Fernández y Martos, 2011.

49 Pérez, 1994, p. 59.
} 
se solicitó la desaparición del Serem, el organismo específico que se había creado en los últimos años del Franquismo, y antecedente directo del Inserso. ${ }^{50}$ Según el activista Antonio Guillén: «entendíamos que las necesidades de las personas con disminución requerían una acción global de Gobierno y tenían que ser abordadas por los diferentes ministerios según sus competencias». ${ }^{51}$

Tras un mes de encierro el 6 de diciembre de 1977, la guardia civil desalojó el local. Recuerda Antonio Guillén:

Acordonaron la sede del Serem (...) y desalojaron uno a uno a los encerrados, teniendo que bajarlos desde cada una de las plantas del edificio (...) ya que antes se había inutilizado el ascensor por parte de los propios encerrados con la idea de dificultar la operación (...) habíamos preparado una serie de medidas (...) permanecer tirados en el suelo, dejar caer nuestros cuerpo, no identificar las sillas de ruedas y prótesis de cada persona, entonar canciones como «No nos moverán...» (...) y efectuar exclamaciones de dolor cuando fuéramos recogidos en brazos. (...) se produjo una actitud contradictoria entre los miembros de las fuerzas policiales, que estuvieron a punto de desobedecer las instrucciones de los mandos por la presión psicológica a la que estaban sometidos. Era la primera vez que debían actuar ante una situación de estas características; a partir de ese momento, y ante cada situación de conflicto, enviaron a los mismos integrantes de esta compañía. ${ }^{52}$

La actuación policial no mermó el empeño del colectivo que, tras intentar permanecer en el cuartel de la Guardia Civil, siguieron su encierro en el suelo del vestíbulo del Palacio de Justicia, y posteriormente en un edificio cedido por el Gobierno Civil. En la comisaria continuó la acción de protesta y ante la negación de dar su dirección, los activistas fueron enviados a los juzgados. Aquí permanecieron un día en el suelo, durmiendo con sacos de dormir, y posteriormente continuaron en un edificio cedido por el Gobierno Civil. ${ }^{53}$

....al negarnos a identificar nuestras sillas de ruedas y prótesis, era imposible movernos. Mientras tanto, desde afuera las personas que no

\footnotetext{
50 Martos, 2015.

51 Guillén, 1994, pp. 64-65.

52 Ibidem, pp. 66-67.

53 El País, 8.12.1977 y El Alcázar, 9.12.1977.
} 
habían sido detenidas continuaron los contactos con personalidades políticas y provocaron que varios abogados fuesen a los juzgados para interesarse por la situación personal de los detenidos. Cuando fueron trasladados a las nuevas dependencias, la fuerza pública se mantuvo continuamente en la puerta impidiendo que aquellos que abandonaran libremente el edificio pudiesen volver a entrar..$^{54}$

Como vemos, durante todo el proceso se realizaron diversos intentos de negociación con entidades públicas, en los que casi siempre la Administración exigió el abandono del encierro como paso previo a la negociación. Según Eugeni, en la mañana del día 6 de diciembre de 1977, una comisión de los encerrados se desplazó al Gobierno Civil de Barcelona para entrevistarse con el gobernador. Al estar el mismo ausente, fueron recibidos por el subgobernador, «quien les manifestó que ya habían hecho bastante saliendo a la calle, y que lo mejor que podían hacer era regresar a casa». ${ }^{55} \mathrm{El}$ punto álgido de las reuniones se dio con el desplazamiento de un grupo de los manifestantes a Madrid, donde apoyado por representantes de UGT se reunieron con el subsecretario del Ministerio de Sanidad, sin obtener grandes avances. A finales de diciembre, y tras el inicio de algunas huelgas de hambre y a pesar del apoyo de los ciudadanos y colectivos diversos, los activistas empezaron a percibir la necesidad de acabar con el encierro, aunque se consensuó terminarlo con una nueva actividad reivindicativa, que fue la toma, de nuevo, del Serem. A las pocas horas de la toma del edificio se inició el desalojo, que esta vez se hizo con la participación de los activistas.

Estos encierros en el Serem, aunque hubo otros análogos en diversos puntos del país, son los más conocidos por su persistencia y el impacto que tuvieron, tanto a nivel local, con la aprobación de importantes medidas en el Ayuntamiento de Barcelona, como por el impulso que dio a la Ley de Integración del Minusválido. Así, por ejemplo, la memoria de los implicados relaciona directamente las mejoras de la ciudad con la actuación de protesta:

En 1978 el Ayuntamiento de Barcelona acordó en fecha 22 de mayo, la realización inmediata de un programa de compra de nuevo material móvil para los transportes públicos de superficie, adquiriendo

\footnotetext{
${ }^{54}$ Guillén, 1994, p. 67.

55 Pérez, 1994, p. 59.
} 
los cinco primeros microbuses con plataforma elevadora para personas con movilidad reducida. (...) En 1979 empezaron a funcionar, y a partir de 1980 se contabilizaron los servicios, aunque no se llegó a cubrir la totalidad de la demanda de los usuarios. ${ }^{56}$

Lo cierto es que poco después del encierro se constituyó la Gestora de Disminuits Físics y Pares de Disminuïts Físics Menors, que se reunió con el alcalde de la capital para presentarle el proyecto de un patronato, que debía estar constituido por todos los grupos afectados que así lo deseasen y recibir el apoyo administrativo y político necesario. Con dificultades este órgano se creó definitivamente en 1979, aunque empezó a funcionar en 1980. En 1981, el Patronato actúo decisivamente en la puesta en marcha de la Ley de Integración Social de los Minusválidos.

En todo caso, la repercusión de estas movilizaciones no se debe entender solamente en función de las respuestas institucionales conseguidas, sino que es necesario considerar tanto su implicación social como personal. Tal como podemos ver en la mayoría de los testimonios de la época, la lucha y movilización fue una vía de autoafirmación, ruptura de barreras y de integración social, y así lo recuerda, por ejemplo, el ya citado Antonio Guillén:

Pero, sin duda, a quienes más marcó el encierro fue a las propias personas con disminución que pudieron vivir durante un mes y medio una nueva realidad marcada por la comprobación de sus propias posibilidades de ser útiles y de poder exigir una vida digna. (...) Esto supuso un enriquecimiento de nuestra experiencia personal, sobre todo si tenemos en cuenta que la mayoría de las personas con disminución que participaban habían tenido enormes dificultades para dotarse de unos mínimos niveles de formación para poder enfrentarse a las exigencias que les suponía incorporarse a la vida social. El encierro resultó ser además un lugar de encuentro con aquellas personas disminuidas que vivían en la más sórdida marginación, que dormían en la vía pública o que presentaban una serie de problemas de personalidad que se sumaban a las dificultades propias de su disminución. ${ }^{57}$

56 Ibidem, pág. 60.

57 Guillén, 1994, p. 65. En un plano mucho más intimista, pero muy interesante para entender la repercusión de esta experiencia, se enmarca este recuerdo de Eugeni Pérez: «Bueno, hay que reconocer que durante todo el tiempo que duró esto, no todo fueron asambleas permanentes; también se practicaron otros ejercicios, y hubo tiempo para ejercitar otros menesteres que aún perduran en el recuerdo con nostalgia. Muchos conocieron 
En los diferentes testimonios que hemos encontrado, especialmente los que se refieren a los primeros años de cambio político, se repite esa ilusión y euforia participativa. En realidad, se trata de un sentimiento general que contagió a todos los actores sociales de la época, y que los investigadores del periodo recogemos de manera recurrente en nuestras entrevistas orales. No obstante, consideramos que, en el caso de las personas con diversidad funcional, esta experiencia tuvo una dimensión mayor, pues supuso una emancipación personal sin precedentes, tal como se muestra en los siguientes testimonios:

...descubro que las personas disminuidas que durante la década de los setenta tuvimos algún protagonismo y responsabilidad en los grupos de base, vivimos los años más creativos e intensos, tanto a nivel personal como a nivel colectivo. Este aspecto contribuyó a que como colectivo disfrutáramos de la mejor etapa en cuanto a participación y presencia activa en la sociedad..$^{8}$

Corrían los años 70. Franco estaba agonizando y yo había encontrado mi causa, un motivo por el que levantarme a diario cargada de proyectos e ilusiones..$^{59}$

Los grises cargaron sobre nosotros, en plena Rambla. De pronto uno de ellos se abalanzó sobre mí y me dio con la porra. Caí de mi sillón de ruedas, rodé por el suelo, y recibí otro golpe en la cabeza. Aquél fue el momento más hermoso de mi vida. Creo que nunca fui más feliz. Es cierto que los golpes me dolieron, es cierto que tuve miedo. Pero ese día me di cuenta que podía ser como los demás. (...) A aquel gris que me sacudía, hubiera querido abrazarlo. Basta de lástima, de indiferencia con nosotros, ¿comprendes? Si no somos buenos para tener trabajo, para tener oportunidades como los demás, por lo menos somos buenos para encajar porrazos. ${ }^{60}$

por vez primera el amor físico, que acabó con la astenia y la sequía de sus intimidades, y se lanzaron como posesos a disfrutar de los mejores goces; también algunos se quedaron en el camino, y sólo queda de ellos las cenizas y el recuerdo». Pérez, 1994, p. 59.

58 Vázquez, 1994, p. 7.

59 Ledesma, 2012, p. 146.

${ }^{60}$ El testimonio estaba firmado por las siguientes siglas: «M.V, 25 años, poliomielítico, parado». Giralt, 1978, pp. 10-11. Sobre la brutalidad policial hacía las personas con diversidad funcional hemos encontrado otras referencias. Así, en las memorias de la revista Voces se señaló: «cuando los subnormales se manifiestan en varias ocasiones a lo largo del año, los «grises» los disuelven como a los normales, es decir, con porras y botes de humo.» En 1979 El País dio noticia de un joven con diversidad funcional física que había participado en una protesta contra la instalación de centrales nucleares. La policía le persiguió y 


\section{Transformación social y actitudes al margen de las grandes movilizaciones}

Como ya dijimos en la introducción de esta aportación, no hay que perder de vista que las movilizaciones más vanguardistas, y su repercusión pública o personal, no dejaron de ser experiencias minoritarias, en relación al amplio y heterogéneo colectivo de personas con diversidad funcional. Así, por ejemplo, fuera de las zonas de gran dinamismo social, las acciones relacionadas con la diversidad funcional tomaron otros cauces menos agresivos, y más acordes con un tejido asociativo más débil. Sin embargo, aun expresándose a través de otras vías, la reivindicación social se dio en todas las provincias de España. Así, si tomamos como ejemplo una provincia rural y poco desarrollada como fue Almería, podemos observar que aún con un cierto retraso temporal, nacieron asociaciones similares a los modelos predominantes en las grandes urbes. Estas organizaciones se concentraron especialmente en la consecución de mejoras prácticas e inmediatas, y para ello utilizaron como principal vía de actuación la difusión de sus necesidades y el contacto directo con las instituciones locales y sus sucesivos dirigentes. Así, por ejemplo, la Asociación Aspapros (Asociación de Padres, Madres y Protectores de Subnormales de Almería), que se había creado como otras asociaciones de esta índole en los años sesenta, se concentró en los proyectos educativos y de ocupación profesional para personas con diversidad funcional intelectual. ${ }^{61}$ Otras de las movilizaciones organizativas de estos años fue la Asociación de Sordos de Almería, que surgió gracias al impulso del joven activista Gregorio Vílchez Rueda. El principal problema de las personas con discapacidad auditiva eran las barreras comunicativas. Durante todo el periodo franquista se había continuado preponderando las llamadas estrategias de

le dio tal paliza que lo dejó en coma. Por otra parte, la activista Carme Serasol puntualizó, recordando la participación en la manifestación masiva del once de septiembre de 1977 en Barcelona: «Éramos muchos minusválidos y nos dieron un sitio preferente para que no nos hiciera daño si había golpes. Íbamos entre los políticos y la gente importante». Respectivamente: Ferrer, 2003, p. 18, El País, 17.1.1979 y Serasols, 1994, p. 160.

${ }_{61}$ Margarita Segura, primera trabajadora social del Colegio «Princesa Sofía» recuerda: «Aspapros nació del fruto de «a dónde van mis hijos cuando tengan 18 años» (...) La asociación jugo un papel muy importante la integración de estos niños, porque ellos solicitaron a la administración apoyo para realizar talleres (...) jugaron un papel muy bueno». Entrevista a Margarita Segura Martínez, Almería, 31.5.2011. De hecho, la organización fue declarada en 1982 de «Utilidad Pública» por el Consejo de Ministros. 
normalización, surgidas a principios de siglo Xx, y que se obstinaban en «modificar» a las personas para igualarlas a su entorno, incluso yendo en detrimento de la funcionalidad. Así, por ejemplo, en el caso de las personas con discapacidad auditiva, los esfuerzos educativos iban encaminados a la «oralidad», una herramienta que era útil para que las personas afectadas expresaran mensajes, pero que, sin embargo, no era la adecuada para crear una verdadera comunicación. Por otra parte, la «oralidad» imposibilitaba por completo la comunicación entre dos personas con discapacidad auditiva, creándose una situación de aislamiento y desconexión, que en gran medida influyó en el escaso desarrollo del asociacionismo en este sector. Conscientes de este atraso, desde hacía un tiempo se estaba empezando a imponer la utilización del lenguaje de signos. En el caso que hemos dicho de Almería, la situación era especialmente lamentable, ya que a mediados de los años setenta prácticamente nadie conocía el lenguaje de signos. Consciente de esta urgencia, el joven granadino Gregorio Vílchez Rueda decidió hacerse cargo del asunto, e inició así de forma autónoma y voluntaria las primeras clases de lenguaje de signos, en un céntrico bar de la capital. El joven, que también sufría una discapacidad auditiva, fue, además, el impulsor del movimiento asociativo, que según recuerda se gestó con grandes dificultades:

...un vecino mío sordo y yo nos fuimos en una moto cerca de Almería a buscar sordos. Les tocábamos de puerta en puerta. ¡Uf! Hacía mucho calor y sudábamos, pero no parábamos. Algunos padres no se fiaban mucho y decían que para qué les queríamos. Les decíamos que nos íbamos a juntar los sordos para hacer una asociación en la capital, para poder tener un futuro con calidad de vida y mejorar en la comunicación con los sordos, es decir, quitar las barreras de comunicación y formar una comunidad de sordos. ${ }^{62}$

Mucho más complicado fue encontrar alguna señal de movilización en los núcleos alejados de la capital provincial. Lo cierto es que, siguiendo con el ejemplo de Almería, el movimiento asociativo prácticamente no existió fuera de la ciudad, debido principalmente a las grandes dificultades de comunicación, importante agravante para la mayoría de personas con diversidad funcional. El propio Gregorio Vílchez recuerda la campaña de difusión que se hizo por la provincia de Almería, y las enor-

62 ASOAL, Historia de la Agrupación de Sordos de Almería, s.f., Archivo de Asoal. 
mes dificultades a las que se enfrentaron: «El tema del carnet del coche era muy complicado, porque ellos no tenían carnet... y entonces, ¿cómo venían?» 63

No obstante, la lejanía física de los centros urbanos no fue la única razón para justificar que un importante número de personas con diversidad funcional no participasen activamente en las movilizaciones. Entre estas personas que no se decantaron por el activismo encontramos tanto la oposición consciente como el conformismo y la resignación, tal como muestran los siguientes fragmentos de entrevistas de la época:

Lo de ahora no lo comprendo. Eso de las barreras arquitectónicas por ejemplo ¿Qué esperamos los minusválidos? ¿Qué nos hagan ciudades para nosotros? Creo que todo este movimiento es contraproducente. Crea ilusiones falsas en muchos inválidos. Quizá sea que, por mi edad, ya no puedo comprenderlos. Un lisiado será siempre un lisiado. ${ }^{64}$

Como toda mujer, quisiera casarme, tener un hogar, hijos. Para una minusválida, esto es un sueño inalcanzable. ¿Qué hacer? (...) La mujer inválida no tiene nada frente a su vida. Quedarse en casa, encerrada, doblemente encadenada: por lisiada y por mujer. Quizás evadirse con la lectura. Algunas estudian, algunas salen a la calle a luchar, en esos movimientos que se han formado ahora. Pero la mayoría se queda en sus casas. ¿Estudiar? ¿y luego qué? ¿Cómo ejercer una profesión en silla de ruedas? Un hombre es distinto. La inteligencia le sirve. La invalidez hasta puede agregarle carácter, darle más energía. Muchos lisiados tienen un hermoso rostro varonil, los hombros fuertes. Pero, ¿una mujer? No, es algo demasiado chocante. ¿Militar en la política? ¿Cómo podría hacerse? No estamos preparadas. La familia se escandalizaría. Habría que romper con todo. Nuestro destino está en la casa. Viviendo para los demás... ${ }^{65}$

En ambos ejemplos vemos el significado complejo de la marginación, con su expresión más cruel en la aceptación de la discriminación como una realidad inamovible y por tanto solamente combatible con la resignación. Además, en el segundo caso la asunción del rol de la mujer, tan interiorizado como el rol del minusválido, nos muestra las diferentes dimen-

63 Entrevista a Gregorio Vílchez Rueda, Almería, 25.6.2011.

${ }^{64}$ Según el texto el testimonio era de «T.R.T, 55 años, invalidez por traumatismo, vendedor de lotería». Giralt, 1978, p. 87.

65 «G.G.Z., 36 años, soltera, parapléjica» en Giralt, 1978, pp. 30-31. 
siones de la presión social y del aislamiento al que estaban condenadas estas personas. La familia era en muchas ocasiones uno de los principales elementos opresores, especialmente en el caso de las mujeres. A propósito, señaló la activista María de los Ángeles Cózar Gutiérrez: «Recuerdo a una chica de mi edad, también con discapacidad, que se pasaba el día sentada en un banquillo en la calle. Le llevaba libros para leer, aunque su madre me dijo un día que no permitiría que su hija fuera una «caldeosa» como yo. Aquella niña estudió y hoy es una mujer independiente. Fue la primera recompensa a esa militancia social». ${ }^{66}$

\section{Conclusiones}

Aguado Díaz calificó a las movilizaciones de finales de los sesenta como «revolución», y aunque su trabajo solo se refería a la «deficiencia mental», es innegable que los cambios conceptuales, sociales y políticos de la época convulsionaron a todo el heterogéneo colectivo que hemos englobado dentro del concepto de diversidad funcional. ${ }^{67}$ En un trabajo posterior, el profesor Jordi Planella calificó los años comprendidos entre 1978 y 1981 como los años de la «insurgencia de la discapacidad», reconociendo la decisiva influencia de estas movilizaciones. ${ }^{68}$ Los recientes historiadores de la diversidad funcional, están recuperando las trayectorias de los activistas, sopesando el significado de estas actitudes disidentes y utilizando este conocimiento para hacer una análisis de la sociedad contemporánea y sus profundos y contradictorios cambios en el umbral del siglo XXI. En el caso español la coincidencia de este movimiento disidente con el proceso de transición a la democracia nos ofrece una investigación aún más rica en matices a la vez que idónea para completar el estudio del cambio político. En la variedad de actitudes frente al proceso de transición, desde el activismo más radical a la pasividad consciente, podemos ver el complejo significado de la marginación social y los múltiples mecanismos que han dificultado la consecución de los derechos de las personas con diversidad funcional. El nuevo marco democrático fue asumido como la deseada oportunidad para acabar con la desigualdad. Las necesidades del sector se leyeron en clave de una

66 Ledesma, 2012, p.146.
67 Aguado, 1995.
68 Planella, 2012, p. 105.

Historia Contemporánea 58, 2018: 747-779 
política social franquista arbitraria y deficiente, aunque también fue cierto que la última década dictatorial había sido el caldo de cultivo en el que se habían gestado estos movimientos sociales. De hecho, la tradicional unión de la discapacidad con los sectores caritativos creó un espacio favorable y de relativa libertad que fue el germen de las movilizaciones más radicales. Algunos asociados recuerdan como sus viajes anuales a Lourdes, meca de enfermos y personas con diversidad funcional a la búsqueda de un milagro, era aprovechada para convivir y compartir con otros jóvenes la experiencia de un país con un sistema político distante al franquismo. La decisiva actitud participativa supuso un auténtico punto de inflexión, tanto a nivel personal como social. La sociedad descubrió con sorpresa que las personas con diversidad no eran «incapacitados» y no sólo reivindicaban sus derechos, sino que además participaban de forma activa en la construcción de la nueva democracia, un horizonte cercano en el que todo parecía posible. No obstante, la generalización de esta afirmación requeriría de una serie de matices, que en esta conclusión solo vamos a señalar a grandes rasgos. En primer lugar, es importante remarcar que, a pesar de haber generalizado el colectivo, los diferentes movimientos asociativos, según la diversidad de sus integrantes, no trabajaron por norma general de una manera conjunta. Las grandes diferencias entre sus integrantes justifican también las diferentes formas y ámbitos de actuación. Así, por ejemplo, las personas con discapacidad visual se esforzaron especialmente para democratizar su organización específica, mientras que las personas con discapacidad auditiva se concentraron en superar la barrera comunicativa y en retomar la actividad asociativa de los años de la República. Por otro lado, mientras que las personas con diversidad funcional física se convirtieron en la vanguardia del movimiento, protagonizando las acciones más representativas, las personas con diversidad funcional intelectual quedaron en un segundo plano, eclipsados por el activismo encabezado por familiares preocupados por su desarrollo educativo y profesional. También, como vimos, hubo diferencias entre las actuaciones de protesta llevadas a cabo en las grandes urbes con las que se desarrollaban en las zonas rurales ya que, al fin y al cabo, el aislamiento físico suponía otra barrera de importancia capital. En general, como hemos referido en diversas ocasiones, las dificultades a las que se afrontaban estas personas eran diarias, e influían de manera determinante en su desarrollo personal y social. En consecuencia, no es de extrañar que su participación en la política requiriese un esfuerzo mayor al de cualquier otro ciudadano. Se- 
gún el presidente de Verdiblanca, José Gómez Amate: «se contaban con los dedos de una mano los que habían cursado bachillerato (...) ¿Cómo podían aquellos jóvenes (...) participar en la vida política con mayúsculas de aquellos años, si la consideración social era de lástima y caridad para las personas con discapacidad?». ${ }^{69}$ Aún más claro es el recuerdo de Gregorio Vílchez: «Nosotros no teníamos ni idea quién era mejor político que otro, porque en realidad no teníamos esa información». ${ }^{70}$ Por lo tanto, viendo las barreras que debían superar diariamente estas personas, y sus dificultades para acceder a derechos básicos como la educación y el empleo, no es de extrañar su ausencia en los puestos representativos o ejecutivos de los partidos políticos. De hecho, quizás no es una casualidad, que la excepción más representativa, Miguel Pereyra, fuese una persona que ya había conseguido una sólida base educativa y un incipiente desarrollo profesional, antes de sufrir el accidente que le cambió la vida.

Sin embargo, como hemos visto, a pesar de las dificultades se gestó un espíritu crítico y un movimiento social, sin el cual nos sería muy difícil entender la creciente concienciación de la sociedad y la evolución política de estos años, simbolizada especialmente en la definitiva aprobación de la Ley de Integración del Minusválidos, en el año 1982. Sin duda, se trataba tan solo de unos pasos decisivos del largo camino hacia una sociedad inclusiva, sin embargo, no podríamos hablar de un proceso hacía la democracia sin tener en cuenta el desarrollo de estos valores, ni a los actores que colaboraron en esta evolución.

\section{Fuentes de archivo}

Archivo Asociación de Personas con Discapacidad Verdiblanca, Almería. Archivo Asociación de Sordos de Almería (ASOAL), Almería.

Archivo Histórico del Partido del Trabajo de España y de la Joven Guardia Roja, on-line: http://www.pte-jgre.com/archivo/archivo.htm

${ }^{69}$ Sagredo, 2000, p. 5.

70 Entrevista a Gregorio Vílchez Rueda, Almería, 25.6.2011. 
Activismo, movimientos y participación social de las personas...

\section{Bibliografía}

Aguado DíAz, Antonio León, Historia de las Deficiencias, ONCE, Madrid, 1995.

Adell ARGILes, Ramón, La transición política en la calle, manifestaciones políticas de grupos y masas: Madrid 1976-1987, Universidad Complutense, Facultad de Ciencias Políticas y Sociología, Madrid,1989.

BRÉGAIN, Gildas, L'internationalisation imparfaite d'une modernité nord-atlantique: essai d'historie croisée des politiques publiques du hándicap en Argentine, au Brésil et en Espagne (1956-1982), Tesis Docotoral, Universidad de Rennes 2, 2014.

Colectivo IOÉ y CIMOP, Discapacidad y trabajo en España. Estudio de los procesos de inclusión y exclusión social de las personas con discapacidad, Inserso, Madrid, 1997.

Cura GonZÁlez, Mercedes del, «La subnormalidad a debate: discursos y prácticas sobre la discapacidad intelectual en el segundo franquismo», en História, Ciências, Saúde, vol. 24, n. ${ }^{\circ} 4$, octubre-diciembre 2016, pp. 1041-1057.

DíAz CASANOva, Máximo, El asociacionismo de los minusválidos: entre organización y movimiento social, Ministerio de Trabajo y Seguridad Social, Madrid, 1985.

Fernández Amador, Mónica y Martos Contreras, Emilia, «La prensa tribuna de los problemas sociales durante la Transición democrática española», Congresso Internacional de História dos Media e do Jornalismo 2011, en: https:// docs.google.com/viewera=v\&pid=sites\&srcid=ZGVmYXVsdGRvbWFpbnx oaXN0b3JpYWRvam9ybmFsaXNtbzIwMTF8Z3g6NGZjMDQzYWFIOTB $1 \mathrm{Mjk} 4 \mathrm{Ng}$ [última consulta 11.08.2017].

Ferrer, Amparo, 25 Años dando Voces, Feaps, Madrid, 2003.

GARVía, Roberto, En el país de los ciegos. La ONCE desde una perspectiva sociológica, Hacer, Barcelona, 1997.

GiRAlt, Federico, Los minusválidos, Dopesa-2, Barcelona, 1978.

GuILlÉn, Antonio, «La participación», en Vilà I MANCEBO, Antoni (ed.), Crónica de una lucha por la igualdad: apuntes para la historia del movimiento asociativo de las personas con discapacidad física y sensorial en Catalunya, Fundación Institut Guttmann, Barcelona, 1994, pp.63-71.

GutiÉRREZ DE TOVAR Y BERUETE, Javier, La creación de la Organización Nacionalde ciegos a través de mis vivencias, ONCE, Madrid, 1988.

Kudlick, Catherine J., «Disability History: Whay We Need Another «Other»», American Historical Review, n. ${ }^{\circ}$ 108, junio 2003, pp. 763-793.

Ledesma Heras, Juan Antonio, Activistas, 15 historias de vida de activistas de la discapacidad, Cermi, Madrid, 2012.

Maravall, José María, La política de la transición, 1975-1980, Taurus, Madrid, 1982.

Historia Contemporánea 58, 2018: 747-779 
Marín ARCE, José María, Los sindicatos y la reconversión industrial durante la transición 1976-1982, Consejo Económico y Social, Madrid, 1997.

Martínez Pérez, José y Cura GonZÁlez, Mercedes del, «El «llamamiento del deber»: influencia exterior, interés del Estado y modernización de las estrategias de gestión de la discapacidad en España (1956-1970), en GoNZÁLEZ MADRID, Damián, OrTiz Heras, Manuel y PÉrez Garzón, J.S. (coord.), $L a$ Historia, Lost in translation?, Universidad de Castilla la Mancha, Cuenca, 2017, pp. 1775-1786.

Martos Contreras, Emilia, «Discapacidad y elecciones: personas minusvaloradas en los inicios de la transición democrática», en Quirosa-ChEYRouze y MuÑoz, Rafael, Navarro Pérez, Luis Carlos y Fernández Amador, Mónica (coords), Las organizaciones políticas, Universidad de Almería, Almería, 2011, pp. 249-262.

Martos Contreras, Emilia, «El primer servicio de atención integral a la diversidad funcional en España: el Serem», en Fernández Amador, Mónica, Martos Contreras, Emilia, Navarro Pérez, Luis Carlos y Quirosa-CheYROUZE Y MUÑOZ, Rafael (edits.), Historia de la Transición en España: las instituciones, Universidad de Almería, Almería, 2015, pp. 741-756.

Martos Contreras, Emilia, «El sindicato de pensionistas y jubilados de CCOO de Almería: nacimiento y desarrollo durante los años de la transición», en Fernández Amador, Mónica (edit.), Miradas al pasado reciente: de la II República a la Transición, Universidad de Almería, Almería, 2014, pp. 317-330.

Martos Contreras, Emilia, Personas mayores y diversidad funcional física e intelectual durante la transición a la democracia, Tesis doctoral, Universidad de Almería, Almería, 2014.

MARTOS CONTRERAS, Emilia, «Sobrevivir a la guerra y a sus consecuencias», en FERNÁNDEZ AMADOR, Mónica (ed.), La guerra civil española, 80 años después. Las investigaciones en la provincia de Almería, Universidad de Almería, Almería, 2016, pp.149-164.

Martos Contreras, Emilia, «Trabajo y minusvalía durante el primer franquismo: La asociación Nacional de inválidos civiles», en GonZÁlez MADRID, Damián, OrTiz Heras, Manuel y Pérez Garzón, J.S. (coord.), La Historia, Lost in translation?, Universidad de Castilla la Mancha, Cuenca, 2017, pp. 2787-2796.

Martos Contreras, Emilia, «Transición y política social: El Instituto Nacional de Servicios Sociales (INSERSO)», en QuiRosa-ChEYRouZE y MuÑoz, Rafael (ed.), Poder y Transición en España. Las instituciones políticas en el proceso democratizador, Biblioteca Nueva, Madrid, 2017, pp. 181-192.

Montoro Martínez, Jesús, Los ciegos en la Historia, ONCE, Madrid, 1991.

NicolaU, R. «El papel de las personas disminuidas en la creación del patronato de disminuidos físicos del Ayuntamiento de Barcelona», en VILÀ I MAN- 
Activismo, movimientos y participación social de las personas...

CEBO, Antoni (ed.), Crónica de una lucha por la igualdad: apuntes para la historia del movimiento asociativo de las personas con discapacidad física y sensorial en Catalunya, Fundación Institut Guttmann, Barcelona, 1994, pp. 111-119.

O'HARA, Susan P., Oral History Interview with Edward V. Roberts, Universidad de California, Berkeley, 1994, en: http://archives.cdn.sos.ca.gov/oral-history/pdf/roberts.-pdf [última consulta 11.08.2017].

Ortiz Heras, Manuel (coord.), Movimientos sociales en la crisis de la dictadura y la Transición: Castilla la Mancha, 1969-1979, Almud, Ciudad Real, 2008.

PÉREZ, Eugeni, «Radiografía de un cuento de nunca acabar», en VILÀ I MANCEBO, Antoni, Crónica de una lucha por la igualdad: apuntes para la historia del movimiento asociativo de las personas con discapacidad física y sensorial en Catalunya, Fundación Institut Guttmann, Barcelona, 1994, pp. 60-72.

PÉreZ-Polo GiL, Maribel, «Miguel Pereyra: La vida sigue y hay que vivirla», $M i$ nusval, n. ${ }^{\circ} 119$, pp. 61-63, 1999.

PereYra, Miguel, «La LISMI, el SEREM y Trías Fargas», cermi.es semanal, 16.04.2012, en: http://semanal.cermi.es/noticia/lismi-serem-tr\%C3\%Adasfargas-miguel-pereyra.aspx, [última consulta 11.08.2017].

Planella Ribera, Jordi, Proyecto Docente: Cátedra de Teoría e Historia de la Educación, Universitat Oberta de Catalunya, Barcelona, 2012.

Planella Ribera, Jordi y PiÉ Balaguer, Assumpció, Militancia y diversidad funcional, Editorial UOC, Barcelona, 2012.

Porras Gallo, María Isabel et al., El drama de la polio. Un problema social y familiar en la España franquista, Catarata, Madrid, 2013.

PuENTE Fuente, César, «Apuntes para una historia sindical en la ONCE», El Bastonazo, n. ${ }^{\circ}$ 15, 2015, PUEDO: Plataforma Unitaria de encuentro para la Democratización de la ONCE, en: http://www.puedo.org/menubastonazo15. htm, [última consulta 11.08.2017].

QuiRosA-ChEYROUZE Y MuÑOZ, Rafael, «El protagonismo de la sociedad en la conquista de la democracia», en QuIROSA-CHEYROUZE Y MuÑOZ, Rafael (coord.), La sociedad española en la Transición: los movimientos sociales en el proceso democratizador, Biblioteca Nueva, Madrid, 2011, pp. 15-23.

Quirosa-CheYrouze y MuÑoz, Rafael (coord.), La sociedad española en la Transición: los movimientos sociales en el proceso democratizador, Biblioteca Nueva, Madrid, 2011.

Quirosa-CheyrouZE Y MuÑOZ, Rafael, «La transición posible a la democracia». en Navajas Zubeldía, Carlos e Iturriaga Barco, Diego (coords.), Crisis, dictaduras, democracia, Universidad La Rioja, Logroño, 2008, pp. 63-70.

REDERO SAN ROMÁn, Manuel, Transición a la democracia y poder político en la España postfranquista (1975-1978), Librería Cervantes, Salamaca, 1993. 
RIERA, Carlos, «Los grupos de base como dinamizadores del movimiento. El papel de los movimientos de base», en VILÀ I MANCEBO, Antoni, Crónica de una lucha por la igualdad: apuntes para la historia del movimiento asociativo de las personas con discapacidad física y sensorial en Catalunya, Fundación Institut Guttmann, Barcelona, 1994, pp. 119-129.

RocA, José M., «Consenso, desmovilización y proceso constituyente en la transición española», Política y Sociedad, n. ${ }^{\circ}$ 16, 1994, pp. 276-281.

Rodríguez SÁncheZ, Juan Antonio, «Las secuelas sociales de la polio: los inicios del movimiento asociativo en España (1957-1975)», Dynamis, n. 32 (2), 2012, pp. 391-414.

ROMAÑACH, Javier y Lobato, Manuel, «Diversidad funcional, nuevo término para la lucha por la dignidad en la diversidad del ser humano», en Foro de Vida Independiente, mayo 2005.

RuIZ, David (dir.), Historia de Comisiones Obreras (1958-1988), Siglo XXI, Madrid, 1993.

RuIZ GIMÉNEZ, J., «La democracia entre el encanto y el desencanto», en VV.AA, Perspectivas de una España Democrática y Constitucionalizada, Unión Editorial, Madrid, 1979. pp. 75-88.

Sagredo Dequero, Manuel, Verdiblanca, Asociación de Minusválidos. 25 año, Diputación de Almería, Almería, 2000.

SERASOLS, Carme, «El movimiento de personas enfermas y con disminuciones orgánicas», en VILÀ I MANCEBo, Antoni, Crónica de una lucha por la igualdad: apuntes para la historia del movimiento asociativo de las personas con discapacidad física y sensorial en Catalunya, Fundación Institut Guttmann, Barcelona, 1994, pp. 151-167.

Soto CARmona, Álvaro, «Conflictividad social y transición sindical», en TuSELL, Javier у Sото, Álvaro, Historia de la transición 1975-1996, Alianza Editorial, Madrid, 1996, pp. 363-408.

Soto CARmona, Álvaro, «Long cycle of social confl ict in Spain (1868-1986)», Review, XVI, n. ${ }^{\circ}$ 2, 1993, pp. 173-197.

Soto Carmona, Álvaro y Aroca Mohedano, Manuela (eds.), Combates por la democracia. Los sindicatos durante la dictadura y la democracia, Fundación Largo Caballero-Universidad Autónoma de Madrid, Madrid, 2012.

Tussel, Javier, La transición española a la democracia, Historia 16, Madrid, 1991.

VÁzQUEZ, M.J., «La normalización: la Lismi», en VILÀ I MANCEBO, Antoni, Crónica de una lucha por la igualdad: apuntes para la historia del movimiento asociativo de las personas con discapacidad física y sensorial en Catalunya, Fundación Institut Guttmann, Barcelona, 1994, pp. 71-75.

Wilhelmi CASANOva, Gonzalo, «No digas que no se puede: luchas de grupos en la transición», en QUIROSA-CHEYROUZE Y MuÑOZ, Rafael (coord.), La socie- 
Activismo, movimientos y participación social de las personas...

dad española en la Transición: los movimientos sociales en el proceso democratizador, Biblioteca Nueva, Madrid, 2011, pp. 287-302.

ZAMEs FleISCHER, Doris y ZAMEs, Frieda, The Disability Rights Movement: From Charity to Confrontation, Temple University Press, Philadelphia, 2001.

\section{Financiación}

Este trabajo ha sido realizado en el ámbito de «Estudios del Tiempo Presente» (PAI HUM-756) y del Centro de Investigación Comunicación y Sociedad (CySoc), y forma parte del proyecto I+D «Políticas sociales e instituciones locales en el tardofranquismo y la Transición. La lucha por la democracia en municipios de Andalucía (1963-1986)», financiado por el Ministerio de Economía y Competitividad (Ref. HAR2017-83744-C3-3-P).

\section{Datos de la autora}

Emilia Martos Contreras (emiliamartoscontreras@gmail.com) es licenciada en Humanidades, tiene dos máster sobre Comunicación Social y es Doctorada con Mención Internacional por la Universidad de Almería. Sus trabajos de investigación se centran en la Historia del Tiempo Presente, especialmente en los problemas sociales, destacando el tema de la diversidad funcional y el de las personas mayores, que fueron el objetivo de su tesis, galardonada con el Premio Extraordinario de Doctorado. También se dedica al análisis de prensa, tanto nacional como internacional. Ha impartido clases en diversas asignaturas universitarias y ha realizado diferentes estancias de investigación, entre ellas en la Universidad Paris-Nanterre y la Autónoma de México. En la actualidad combina las labores de investigación y enseñanza universitaria con la docencia bilingüe en un centro de secundaria. 